DOI: $10.5902 / 198346596590$

\title{
GESTÃO DE PROJETOS DE EVENTOS CULTURAIS EM UMA UNIVERSIDADE PÚBLICA FEDERAL: ANÁLISE DE PRÁTICAS E PROPOSIÇÃO DE MELHORIAS
}

\author{
PROJECT MANAGEMENT OF CULTURAL EVENTS \\ IN A PUBLIC UNIVERSITY: ANALYSIS OF PRACTICES AND \\ IMPROVEMENT PROPOSITIONS
}

\author{
Recebido 25/09/2012 \\ Aceito 10/12/2012 \\ Cláudia Fabiana Gohr ${ }^{1}$ \\ Luciano Costa Santos ${ }^{2}$ \\ Ângela Watte Schwingel ${ }^{3}$ \\ Edson Talamini ${ }^{4}$
}

\section{RESUMO}

Este artigo tem como principal objetivo descrever as práticas de gestão de projetos de eventos culturais adotadas pela Coordenadoria de Cultura (COC) de uma universidade pública federal, identificando pontos críticos e fornecendo base para a elaboração de uma metodologia específica para a organização pesquisada. A pesquisa adotou uma abordagem de análise predominantemente qualitativa, tanto para a identificação de práticas junto aos responsáveis pelo gerenciamento de projetos quanto para a condução de um estudo de caso sobre um projeto realizado pela instituição. Os dados foram coletados por meio de entrevista semiestruturada, observação participante e análise documental. Foi possível constatar que o gerenciamento e a organização de projetos de eventos na universidade estudada apresentam algumas peculiaridades, o que requer o desenvolvimento de processos singulares para a sua gestão. Além disso, quando comparada com as melhores práticas sugeridas na literatura, a gestão de projetos de eventos na universidade ainda se encontra em um estágio incipiente. Com base nos resultados, foram apresentadas algumas proposições de melhorias para a gestão de projetos de eventos culturais na COC, principalmente em relação à adoção de ferramentas de gestão de projetos e às atividades que devem ser executadas em cada uma das fases do ciclo de vida de um evento cultural.

Palavras-chave: Gestão de Projetos; Gestão de Eventos; Eventos Culturais.

\footnotetext{
Possui graduação em Ciências Econômicas pela Universidade Federal de Santa Catarina - UFSC, mestrado e doutorado em Engenharia de Produção pela Universidade Federal de Santa Catarina - UFSC. Atualmente é professora da Universidade Federal do Paraíba - UFPB. João Pessoa, Paraíba, Brasil. E-mail: claudiagohr@ct.ufpb.br.

2 Possui graduação em Engenharia Civil pela Universidade Federal do Espírito Santo - UFES, mestrado e doutorado em Engenharia da Produção pela Universidade Federal de Santa Catarina - UFSC. Atualmente é professor da Universidade Federal da Paraíba - UFPB. João Pessoa, Paraíba, Brasil. E-mail: luciano@ct.ufpb.br.

${ }^{3}$ Universidade Federal da Grande Dourados - UFGD. E-mail: angelaschwingel@ufgd.edu.br.

${ }^{4}$ Possui graduação em Ciências Econômicas pela Universidade de Passo Fundo - UPF, mestrado e doutorado em Agronegócios pela Universidade Federal do Rio Grande do Sul - UFRGS. Atualmente é professor da Universidade Federal do Rio Grande do Sul - UFRGS. Porto Alegre, Rio Grande do Sul, Brasil. E-mail: edson.talamini@ufrgs.br.
} 


\section{ABSTRACT}

This article aims to describe the management practices used for conducting cultural events adopted by the Department of Culture of a public university, identifying critical points and providing the basis for developing a specific methodology for the organization. The research adopted a qualitative approach of analysis, both to identify practices with those responsible for project management and for conducting a case study of a project undertaken by the institution. For data collection we used semi-structured interviews, participant observation and document analysis. It was found that the project management of cultural events at the university has some quirks, which requires the development of specific processes for their management. Moreover, when compared with the best practices suggested by the literature, the project management of events conducted by the university is still at an incipient stage of maturity. Based on the results, we presented some proposals for improvement for the project management of cultural events in the Department of Culture, especially regarding the adoption of management tools for projects and activities that must be performed at each stage of the life cycle of a cultural event.

Keywords: Project Management; Event Management; Cultural Events.

\section{INTRODUÇÃO}

Os projetos representam instrumentos de mudança e desenvolvimento nas organizações, que, cada vez mais, procuram capacitar-se para o gerenciamento de múltiplos projetos (DOOLEY; LUPTON; O'SULLIVAN, 2005). Devido à sua relevância, a Gestão de Projetos transformou-se em uma disciplina fundamental para a gestão empresarial, pois, dentre outros fatores, os projetos são importantes meios de implementação da estratégia (YOUNG et al., 2012; MORRIS; JAMIESON, 2005; LONGMAN; MULLINS, 2004). O gerenciamento de projetos envolve as atividades típicas relacionadas ao seu ciclo de vida, isto é, iniciação, planejamento, execução, controle e finalização do projeto (PMI, 2004). Assim, a gestão eficiente de projetos depende da aplicação de conhecimentos, habilidades e ferramentas nas diferentes etapas do ciclo de vida do projeto (DINSMORE; SILVEIRA NETO, 2004).

A organização de um evento, devido às suas características, pode ser caracterizada como um projeto (PEREIRA; CANTO, 2009). Por outro lado, a metodologia genérica de gestão de projetos pode ser aplicada a qualquer conjunto de atividades (LASZLO, 1999), inclusive às atividades de gestão de eventos. Nesse contexto, este artigo tem como principal objetivo descrever as práticas de gestão de projetos de eventos culturais adotadas pela Coordenadoria de Cultura (COC) de uma universidade pública federal, permitindo identificar os principais fatores críticos relacionados à gestão de projetos culturais na organização estudada. A identificação das práticas de gestão de projetos permitiu que pudessem ser sugeridas melhorias para a organização, visando, para o futuro, ao desenvolvimento de uma metodologia própria para a gestão de eventos na COC.

Em se tratando de gestão de eventos, ainda são poucas as pesquisas que abordam o tema pela ótica da gestão de projetos, pois, como os eventos geralmente estão relacionados à atividade turística, grande parte das pesquisas trata os eventos sob o enfoque do turismo (REVERTÉ; IZARD, 2011). Por outro lado, mesmo na literatura específica de gestão de eventos, observa-se uma escassez de pesquisas que tratam das peculiaridades dos eventos culturais.

Desde a sua criação, a $\mathrm{COC}$ da organização estudada vem realizando vários eventos culturais que visam à integração da universidade com a comunidade do município em que se situa, sendo considerada uma das maiores promotoras de eventos culturais de sua região. Assim, estudar seu processo de gerenciamento de eventos culturais tem grande relevância, pois pode auxiliar o gestor de eventos no que tange às diferentes atividades relacionadas ao ciclo de vida 
do projeto.

De um modo geral, as peculiaridades na gestão universitária aumentam a complexidade na condução das diferentes atividades que compõem a função social das instituições de ensino superior (CASADO; SILUK; ZAMPIERI, 2013; GALVÃO; CORRÊA; ALVES, 2011). Portanto, também é possível identificar a relevância deste trabalho ao situar sua contribuição no escopo da gestão universitária.

Após esta introdução, é apresentada uma breve revisão de literatura sobre gestão de projetos e de eventos. Os procedimentos metodológicos são descritos posteriormente, para, em seguida, as práticas analisadas de gestão de projetos de eventos culturais serem apresentadas, assim como os fatores críticos relacionados à sua gestão. $O$ texto encerra-se com as conclusões do trabalho e as sugestões para futuras pesquisas.

\section{GESTÃO DE PROJETOS}

De acordo com o PMI (2004, p. 5), projeto é "um esforço temporário empreendido para criar um produto, serviço ou resultado exclusivo". Os projetos diferenciam-se dos processos organizacionais, pois estes são operações contínuas e repetitivas, enquanto aqueles fazem algo novo, uma única vez (BROWNING, 2010). São características de um projeto: a presença de um objetivo bem definido, a complexidade (múltiplas atividades, múltiplos recursos compartilhados), a unicidade, a incerteza, a natureza temporária e o ciclo de vida (PRADO, 2004; CARVALHO; RABECHINI JR., 2005). Em função dessas características, os projetos necessitam de um tratamento diferenciado no que tange ao seu gerenciamento. A natureza temporária do projeto conduz ao seu ciclo de vida, que está relacionado à sequência de fases para seu desenvolvimento, conforme pode ser observado no quadro 1.

\begin{tabular}{|c|c|}
\hline Etapas & Características \\
\hline Iniciação & $\begin{array}{l}\text { - Ponto de partida do projeto, tendo início com a ideia do que será feito. } \\
\text { - Consideração das metas preliminares e das ideias iniciais sobre custo-benefício, via- } \\
\text { bilidade, perspectivas, áreas problemáticas e abordagens alternativas. } \\
\text { - Definição da proposta do projeto (justificativa, métodos propostos, benefícios e cus- } \\
\text { tos etc.) } \\
\text { - Realização do estudo de viabilidade do projeto. }\end{array}$ \\
\hline Planejamento & $\begin{array}{l}\text { - Planejamento formal do projeto e esclarecimento dos objetivos. } \\
\text { - Planejamento da estrutura e da administração do projeto e seleção da equipe. } \\
\text { - Criação de planos de atividade, finanças e recursos, os quais são integrados com pa- } \\
\text { drões de normas de qualidade, segurança, comunicação e administração. } \\
\text { - Criação de planos de análise de progresso do ciclo de vida do projeto. }\end{array}$ \\
\hline $\begin{array}{l}\text { Implementação } \\
\text { (execução) }\end{array}$ & $\begin{array}{l}\text { - Os planos são postos em operação. } \\
\text { - Controle, monitoramento e coordenação de cada, seguindo os objetivos do projeto. } \\
\text { - Realização das análises de progresso e atualização ou revisão dos planos. }\end{array}$ \\
\hline $\begin{array}{l}\text { Monitoramento } \\
\text { e Controle }\end{array}$ & $\begin{array}{l}\text { - Verificação e controle do escopo, do cronograma, dos custos, da qualidade e dos ris- } \\
\text { cos. } \\
\text { - Gerenciamento da equipe do projeto. } \\
\text { - Relatórios de desempenho e gerenciamento das partes interessadas. } \\
\text { - Administração dos contratos. }\end{array}$ \\
\hline Encerramento & $\begin{array}{l}\text { - Preparação para a conclusão e a entrega, atribuição de deveres e responsabilidades. } \\
\text { - Análise e avaliação do projeto. }\end{array}$ \\
\hline
\end{tabular}

Fonte: PMI (2004).

Existem diferentes fatores críticos que influenciam no sucesso de um projeto, tais como 
os aspectos denominados por Bryde (2003) de "triângulo de ferro", relacionados ao trade-off entre custo, tempo e qualidade. Ainda de acordo com o autor, existem vários agentes (stakeholders) que influenciam nos projetos, portanto, há a necessidade de atendimento das necessidades e expectativas desses stakeholders.

O gerente do projeto representa um dos stakeholders mais importantes e é o responsável por todas as etapas do ciclo de vida, considerando que a essência da gestão de projetos é o planejamento e a execução das atividades para que o produto seja entregue de acordo com as restrições de qualidade, prazo e custo. Destaca-se, ainda, que verificar o sucesso de um projeto não é uma tarefa fácil, pois o sucesso é um conceito complexo e ambíguo que muda ao longo das diferentes etapas do ciclo de vida (DUARTE et al., 2012; MALACH-PINES; DVIR; SADEH, 2009; JUGDEV; MÜLLER, 2005).

A gestão de projetos é um esforço temporário que visa ao alcance de determinados objetivos previamente estabelecidos (DINSMORE; SILVEIRA NETO, 2004; PRADO, 2004). Trata-se de uma atividade multidisciplinar, que envolve a integração de diversos especialistas. Do ponto de vista organizacional, a gestão de projetos requer o aprimoramento e o desenvolvimento de áreas específicas do conhecimento, conforme o modelo proposto pelo PMI (2004) (quadro 2).

\begin{tabular}{|c|c|}
\hline Áreas de conhecimento & Principais características \\
\hline Gestão da Integração & $\begin{array}{l}\text { - Integrar todas as áreas e administrar um sistema de controle das alte- } \\
\text { rações. }\end{array}$ \\
\hline Gestão do Escopo & $\begin{array}{l}\text { - Definir o produto e as delimitações do projeto. } \\
\text { - Gerenciar as atividades para que tudo ocorra dentro do ciclo de vida. }\end{array}$ \\
\hline Gestão do Tempo & - Estimar e controlar a duração das atividades. \\
\hline Gestão de Custos & - Avaliar recursos quanto a seus custos (orçamento). \\
\hline Gestão da Qualidade & - Assegurar a satisfação dos clientes e dos demais interessados. \\
\hline Gestão de Recursos Humanos & $\begin{array}{l}\text { - Planejar, organizar, montar e controlar a equipe, buscando produzir os } \\
\text { melhores resultados e o desenvolvimento profissional. }\end{array}$ \\
\hline Gestão das Comunicações & - Garantir o fluxo de informações, sua eficiente utilização e o registro. \\
\hline Gestão dos Riscos & - Reconhecer os riscos do projeto, identificar e avaliar. \\
\hline Gestão de Suprimentos & - Obter os recursos estipulados no orçamento. \\
\hline
\end{tabular}

Quadro 2 - Áreas do conhecimento de gestão de projetos.

Fonte: PMI (2004).

Para uma melhor eficiência no gerenciamento de projetos, foram surgindo diferentes metodologias de gestão ao longo dos anos. Para o PMI (2004, p. 85), "uma metodologia de gerenciamento de projetos define um conjunto de grupos de processos de gerenciamento de projetos, seus processos relacionados e as funções de controle relacionadas que são consolidados e combinados para formar um todo unificado funcional". Assim, muitas organizações com experiência na área têm desenvolvido suas próprias metodologias (metodologias singulares), que geralmente são criadas quando a organização atinge um alto grau de maturidade em gestão de projetos (RABECHINI JR.; PESSÔA, 2005). De acordo com Rabechini Jr. e Pessôa (2005), uma organização atinge a maturidade na gestão de projetos quando reconhece a possibilidade de obter a combinação de várias metodologias dentro de uma única.

A utilização de metodologias específicas de gerenciamento de projetos pode trazer diversos benefícios para as organizações que as adotam. Dentre esses benefícios, Kerzner (2006) destaca que em curto prazo os benefícios típicos são a redução nos custos, a maior facilidade em cumprir o cronograma e a melhoria na comunicação e no feedback entre os stakeholders. Em 
longo prazo, o autor destaca a redução de riscos, a melhoria na tomada de decisão, o aumento da confiança e da satisfação do cliente e o uso de mecanismos de controle mais rígidos.

Tendo em vista que o presente trabalho se propõe a descrever as práticas de gestão de eventos adotadas pela Coordenadoria de Cultura de uma universidade federal, para que posteriormente se possa adequar essas práticas à realidade dos eventos culturais, a próxima seção discute a forma como a gestão de eventos é tratada na literatura da área.

\section{GESTÃO DE EVENTOS}

Eventos são caracterizados como acontecimentos especiais (rituais, apresentações ou celebrações) que possuem um determinado objetivo (cultural, social ou empresarial), portanto devem ser planejados, organizados, coordenados e controlados (ALLEN et al., 2003; BRITTO; FONTES, 2002). De acordo com Canton (1998), um evento também pode ser definido como ações de profissionais por meio de realização de pesquisa, planejamento, organização, coordenação, controle e implantação de um projeto independente que visa atingir um determinado público-alvo com ações concretas e resultados projetados. Assim, um evento é um "fato ou acontecimento espontâneo ou organizado, ocorrido na sociedade, que sob o ponto de vista do profissional pressupõe planejamento e organização" (CANTON, 1998, p.102).

De uma forma geral, os autores têm classificado os eventos de diferentes formas, dividindo-os segundo categorias, áreas de interesse, tipo de público, frequência com que ocorrem, conteúdo, entre outros (MARTIN, 2003; BRITTO; FONTES, 2002). De acordo com esses autores, especificamente em se tratando de eventos culturais, estes podem ser enquadrados por área de interesse, sendo exemplos os festivais de música, de teatro, de folclore e de cinema; as exposições de arte, os lançamentos de livros etc. Assim, um evento cultural pode ser definido como experiências únicas que podem criar um contexto social e espacial para o desenvolvimento de relações humanas, com a finalidade de transmitir objetivos concretos para uma determinada população (REVERTÉ; IZARD, 2011).

Como um evento possui as mesmas etapas do ciclo de vida de um projeto, que deve ser desenvolvido de acordo com parâmetros de tempo, custo e qualidade, a sua gestão segue o procedimento natural da gestão de projetos. Na gestão de um evento, também existem diferentes tipos de stakeholders (primários: trabalhadores, voluntários, patrocinadores, fornecedores, espectadores e pessoas participantes; e secundários: governo, comunidade, serviços de emergência, negócios em geral, mídia e organizações de turismo) e o seu envolvimento no processo de planejamento do evento pode auxiliar no sucesso deste (REID, 2011).

Como em qualquer outra atividade empresarial, um evento também envolve um processo de planejamento, que está relacionado com suas diferentes fases. Nesse sentido, os projetos de eventos culturais possuem objetivos, estratégias e planos de ação, assim como mecanismos de avaliação e controle (ver figura 1). No entanto, assim como em qualquer projeto, o planejamento de um evento assume um caráter temporário.

Para que o planejamento e a organização do evento sejam feitos de maneira mais concisa, é adequado que o processo siga algumas fases (MARTIN, 2003):

a) Pré-evento: é a definição do projeto e o planejamento de todas as suas etapas. Essa também é a fase de definição de receitas e despesas esperadas, tipos de fornecedores e equipe a ser contratada, conforme com os objetivos do projeto. De acordo com Canton (1998), a proposta inicial do projeto de um evento deve ser embasada em conhecimentos técnicos, criativos e convincentes, pois tais aspectos são importantes instrumentos para a viabilidade e a qualidade de um evento. 
b) Evento: é a organização do evento propriamente dita, em que acontece a montagem do evento no local escolhido e a operacionalização das atividades.

c) Pós-evento: é a desmontagem da estrutura do evento, os acertos financeiros e os pagamentos, assim como o encerramento de todas as atividades.

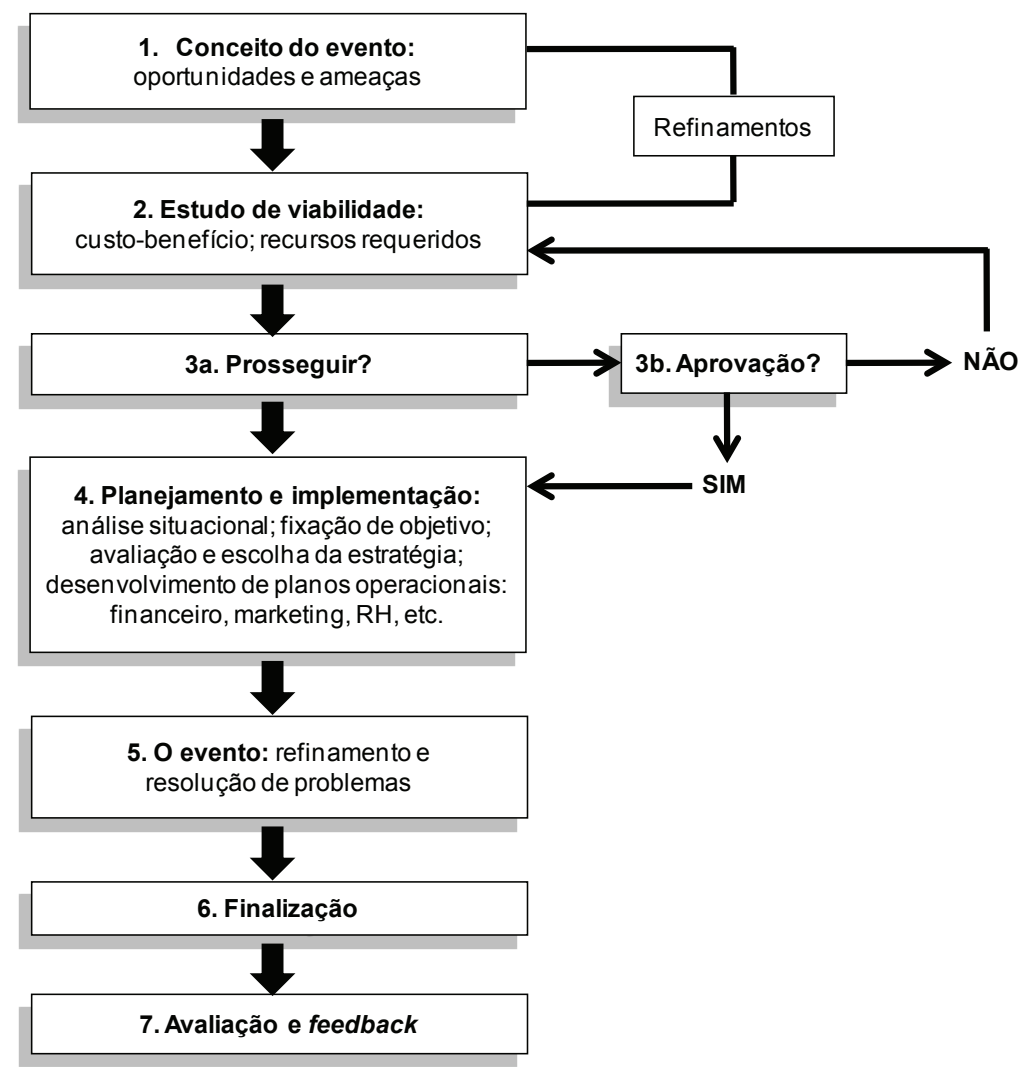

Figura 1 - O processo de planejamento de um evento.

Fonte: Baseado em Allen et al. (2003).

De acordo com o exposto, pode-se verificar que a gestão de um projeto de evento também envolve as diferentes áreas de conhecimento propostas pelo PMI (2004) e expostas no quadro 2, apresentado anteriormente. Convém destacar que o planejamento de um evento envolve o desenvolvimento de uma equipe que compreenda claramente o motivo da existência do projeto, com o estabelecimento de uma estrutura organizacional adequada e a definição de objetivos e estratégias. Para Canton (1998), a formação de uma equipe de apoio coesa e eficiente, exposta em um organograma adequado, é fundamental para o sucesso de um evento. Tais estratégias devem seguir planos operacionais (de marketing, de recursos humanos e financeiros, de qualidade, entre outros) e necessitam de um processo de avaliação, controle e feedback.

Enfim, a organização do evento é um trabalho complexo, sendo necessária a presença de um gerente de projeto que coordene e controle as suas diferentes etapas. $O$ gerente do evento precisa ter uma visão técnica sobre sua organização e também uma visão global sobre o momento de sua atuação (CANTON, 1998). Ao examinar a literatura das áreas de gestão de projetos e de gestão de eventos, é possível verificar que as duas áreas se complementam e, como se observa no quadro 3, têm mais aspectos em comum do que divergências. 


\begin{tabular}{|l|l|l|}
\hline $\begin{array}{l}\text { Etapas do ciclo } \\
\text { de vida }\end{array}$ & Gestão de Projetos & Gestão de Eventos \\
\hline Iniciação & $\begin{array}{l}\text { - Ponto de partida do projeto, com defi- } \\
\text { nição de metas, ideias iniciais, custo-be- } \\
\text { nefício, viabilidade, perspectivas, entre } \\
\text { outros. } \\
\text { - Definição da proposta do projeto. } \\
\text { - Realização do estudo de viabilidade. }\end{array}$ & $\begin{array}{l}\text { - Criação do pré-projeto do evento, iden- } \\
\text { tificando necessidades e oportunidades e } \\
\text { definindo objetivos, recursos, despesas, } \\
\text { recursos humanos, entre outros. } \\
\text { - Realização do estudo de viabilidade. }\end{array}$ \\
\hline Planejamento & $\begin{array}{l}\text { - Planejamento da estrutura de gestão } \\
\text { do projeto e seleção da equipe. } \\
\text { - Criação dos planos. }\end{array}$ & $\begin{array}{l}\text { - Análise do estudo de viabilidade. } \\
\text { - Planejamento e desenvolvimento de pla- } \\
\text { nos funcionais (recursos humanos, financei- } \\
\text { ros, suprimentos, riscos etc.). }\end{array}$ \\
\hline $\begin{array}{l}\text { Implementação } \\
\text { (execução) }\end{array}$ & $\begin{array}{l}\text { - Orientação e gerenciamento da exe- } \\
\text { cução. }\end{array}$ & $\begin{array}{l}\text { - Execução dos planos e realização. } \\
\text { - Refinamento e resolução de problemas. }\end{array}$ \\
\hline Monitoramento Controle & $\begin{array}{l}\text { - Controle e monitoramento do trabalho } \\
\text { do projeto, bem como controle de mu- } \\
\text { danças, do escopo, do cronograma, de } \\
\text { custos. } \\
\text { - Gerenciamento da equipe do projeto. }\end{array}$ & $\begin{array}{l}\text { - Planos e sistemas de controle correspon- } \\
\text { dentes aos planos funcionais. }\end{array}$ \\
\hline - Prestação de contas e relatórios finais.
\end{tabular}

Quadro 3 - Comparação entre as abordagens de gestão de projetos e gestão de eventos.

Após a revisão sobre os conceitos de gestão de projetos (abordagem genérica) e de gestão de eventos (abordagem específica), pode-se identificar que as duas áreas têm um potencial de contribuição mútua para compor uma metodologia singular de gestão de projetos de eventos.

\section{PROCEDIMENTOS METODOLÓGICOS}

As etapas da operacionalização da pesquisa podem ser visualizadas na figura 2. No quadro 4, é possível observar as principais técnicas de coleta de dados adotadas nas diferentes fases da pesquisa, assim como a sua finalidade.

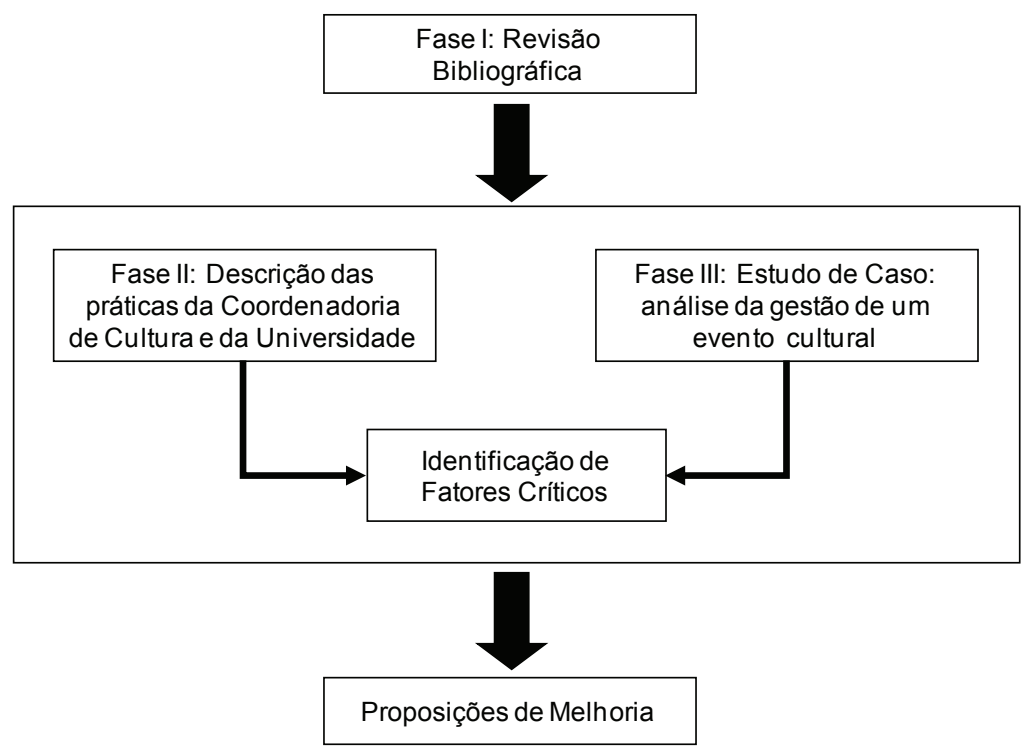

Figura 2 - Fases da pesquisa. 
GESTÃO DE PROJETOS DE EVENTOS CULTURAIS EM UMA UNIVERSIDADE PÚBLICA FEDERAL: ANÁLISE DE PRÁTICAS E PROPOSIÇÃO DE MELHORIAS

\begin{tabular}{|c|c|l|}
\hline Fase & \multicolumn{1}{|c|}{ Técnica } & Finalidade \\
\hline \multirow{2}{*}{ I } & $\begin{array}{c}\text { Revisão } \\
\text { bibliográfica }\end{array}$ & $\begin{array}{l}\text { - Identificar semelhanças e diferenças na literatura de gestão de projetos e } \\
\text { de organização de eventos. } \\
\text { - Apoiar a realização da pesquisa de campo e a proposição de melhorias. }\end{array}$ \\
\cline { 2 - 4 } & $\begin{array}{c}\text { Entrevista } \\
\text { semiestruturada }\end{array}$ & $\begin{array}{l}\text { - Identificar fatores críticos relacionados às práticas de gestão de eventos } \\
\text { culturais na universidade de uma forma geral e na Coordenadoria de Cultu- } \\
\text { ra. }\end{array}$ \\
\hline \multirow{2}{*}{ III } & $\begin{array}{c}\text { Anarlise documão } \\
\text { e observação } \\
\text { participante }\end{array}$ & $\begin{array}{l}\text { - Descrever as práticas de gestão de eventos da COC. } \\
\text { - Identificar fatores críticos relacionados às práticas de gestão de eventos } \\
\text { da COC. }\end{array}$ \\
\hline & $\begin{array}{l}\text { - Analisar como é realizada a gestão de projetos na COC por meio de um } \\
\text { - Identificar deficiências e pontos positivos na gestão de um evento na prática. } \\
\text { - Auxiliar na proposição de melhorias para a gestão de projetos de eventos } \\
\text { culturais realizados pela COC. }\end{array}$ \\
\hline
\end{tabular}

Quadro 4 - Técnicas de coleta de dados adotadas na pesquisa.

A seguir, são apresentados maiores detalhes sobre cada uma das fases desta pesquisa.

- Fase I - Levantamento bibliográfico. Feito em artigos recentes de periódicos acessados por meio das bases de dados que compõem o Portal de Periódicos da CAPES e a base SCIELO (Scientific Electronic Library Online). Também foram pesquisados livros de autores renomados na área de investigação.

- Fase II - Descrição das práticas de gestão de eventos da COC e da universidade objeto de investigação. Para a descrição das práticas de gestão de eventos da COC, foi utilizada em um primeiro momento a observação participante, pois um dos pesquisadores trabalhava nesse órgão e adotou um procedimento estruturado para a análise de práticas. Nessa técnica, o pesquisador se integra ao objeto de pesquisa, participando de alguma forma na atividade pesquisada (AZEVEDO; AZEVEDO, 2008; LAKATOS; MARCONI, 1990). Além disso, foi realizada a entrevista semiestruturada com o Coordenador de Cultura, com o Secretário Administrativo da Coordenadoria de Cultura, com o Assessor de Comunicação Social e com o Assessor da Pró-Reitoria de Extensão e Cultura. Os dois últimos entrevistados representavam sujeitos de pesquisa externos à COC e forneceram informações importantes sobre o procedimento geral de gestão de eventos na universidade, realizado por qualquer órgão.

- Fase III - Estudo de caso. Para enriquecer os dados coletados diretamente com os entrevistados, optou-se por analisar o caso da "Mostra de Teatro 2010", um evento realizado pela COC durante o período da pesquisa. $O$ estudo de caso foi realizado a partir da análise documental, em que foram analisados os relatórios e os documentos que representavam a memória descritiva do evento. Além disso, contribuiu para o estudo o fato de um dos autores ter participado desse projeto, adotando a postura de observação passiva, sem interferir na prática realizada.

A análise das informações da pesquisa de campo foi feita por meio da análise de conteúdo, uma técnica que permite a descrição objetiva e sistemática do conteúdo contido nos dados coletados (AZEVEDO; AZEVEDO, 2008). A análise de conteúdo é um método de pesquisa flexível, que pode ser aplicado a diversos problemas relacionados a diferentes áreas do conhecimento, integrando métodos típicos das ciências sociais aplicadas (WHITE; MARSCH, 2006).

\section{ESTUDO EMPÍRICO}

A organização estudada é uma instituição federal de ensino superior que possui três linhas de atuação: ensino, pesquisa e extensão. A extensão tem como finalidade o relacionamento 
da universidade com a comunidade externa. A Pró-Reitoria de Extensão, Cultura e Assuntos Estudantis é a responsável por esse relacionamento e subordinada a ela encontra-se a Coordenadoria de Cultura ( $\mathrm{COC})$, responsável pela gestão dos eventos culturais realizados pela universidade. Esta seção apresenta, inicialmente, as práticas de gestão de projetos adotadas pela COC e pela universidade estudada. Posteriormente, analisa-se a gestão de projetos de eventos culturais na $\mathrm{COC}$ por meio do estudo de caso, para em seguida apresentar os fatores críticos relacionados às práticas de gestão de eventos culturais, assim como as principais proposições de melhoria.

\subsection{Práticas de gestão de eventos da COC e da universidade}

Dentro da COC a oportunidade de criação de um projeto pode ser realizada de duas formas: (i) projetos que visam atender à demanda da própria comunidade, sejam carências dentro da universidade ou da comunidade em geral; (ii) projetos que atendem à oferta proveniente dos órgãos financiadores da cultura, como o Ministério da Cultura, a Petrobrás, entre outros, os quais abrem editais para determinadas áreas culturais, como artes cênicas, dança, festivais de música, literatura etc. Nos demais órgãos que participam da organização de eventos dentro da universidade, a proposta é proveniente da Reitoria ou das Faculdades. Considerando as típicas áreas do conhecimento de gestão de projetos apresentadas no quadro 2, a COC e os outros órgãos da universidade desenvolvem as atividades citadas no quadro 5 .

\begin{tabular}{|c|c|}
\hline Áreas & Atividades \\
\hline Integração & $\begin{array}{l}\text { - Estudo de viabilidade: é desenvolvido informalmente. Verifica-se a viabilidade diante dos mate- } \\
\text { riais disponíveis para a sua realização. Não há uma ferramenta que auxilie nesse processo. } \\
\text { - Abertura: cadastramento em um sistema informatizado de registro e controle de projetos - SigProj. } \\
\text { - Após a realização do cadastro no SigProj, o projeto deve ser aprovado pelos seguintes órgãos: } \\
\text { Pró-Reitoria de Extensão e Cultura; Câmara de Extensão e Cultura; Conselho de Ensino, Pesqui- } \\
\text { sa, Extensão e Cultura. Se aprovado por todas as instâncias, o projeto poderá ser executado. }\end{array}$ \\
\hline Escopo & $\begin{array}{l}\text { - É planejado conforme o projeto cadastrado no SigProj, no qual são discriminadas as ati- } \\
\text { vidades a serem realizadas e as demais informações. Ferramentas utilizadas: planilhas do } \\
\text { SigProj e pauta de divisão (incluem-se as atividades a serem desenvolvidas e estimam-se as } \\
\text { necessidades do projeto). } \\
\text { - Ferramentas de suporte: de acordo com o secretário da COC, o processo é essencialmente } \\
\text { empírico, sem uma ferramenta específica para planejamento e gestão do escopo. }\end{array}$ \\
\hline $\begin{array}{l}\text { Recursos } \\
\text { humanos }\end{array}$ & $\begin{array}{l}\text { - O gerente dos projetos culturais é invariavelmente o Coordenador de Cultura. Nos demais } \\
\text { setores, o coordenador é o proponente do projeto. } \\
\text { - O coordenador responde pelo projeto e delega funções aos membros da equipe; suas } \\
\text { obrigações e responsabilidades são descritas e cadastradas no SigProj. } \\
\text { - Equipe: pessoas que atuam no próprio setor proponente do projeto, tendo suas atividades } \\
\text { são definidas a partir do cargo que ocupam e das habilidades pessoais. Outros órgãos que } \\
\text { geralmente dão apoio: Coordenadoria de Gestão de Recursos Orçamentários e Financeiros, } \\
\text { Divisão de Compras e Assessoria de Comunicação (sendo responsável pela divulgação e } \\
\text { pelo cerimonial). } \\
\text { - O apoio técnico é dado pelas empresas prestadoras de serviços que são licitadas pela Instituição. } \\
\text { - Não se utilizam de ferramentas de apoio; todas as ações são baseadas na experiência. }\end{array}$ \\
\hline Tempo & $\begin{array}{l}\text { - Planejamento, duração, sequenciamento e recursos são baseados nas necessidades do } \\
\text { projeto. Duração e sequenciamento das atividades são planejados de acordo com a experi- } \\
\text { ência e a análise de eventos anteriores; fazem-se cálculos estimados, mas não formalmen- } \\
\text { te. }\end{array}$ \\
\hline Riscos & $\begin{array}{l}\text { - Práticas na COC e na Instituição são equivalentes. A identificação é feita com o planeja- } \\
\text { mento, podendo ou não inviabilizar o projeto. Pode ser elaborado um plano para contin- } \\
\text { gências ("plano B"). }\end{array}$ \\
\hline
\end{tabular}




\begin{tabular}{|c|c|}
\hline Áreas & Atividades \\
\hline Custos & $\begin{array}{c}\text { - Consultam-se as instâncias superiores da Instituição (Reitoria e Pró-Reitorias), as quais dão } \\
\text { o aval para a utilização do recurso. O uso de recursos externos é levado em consideração. } \\
\text { - Estimativa de custos e orçamentação são baseadas nos itens que o projeto utilizará. Para } \\
\text { isso, é realizada uma pesquisa de mercado e são solicitados no mínimo orçamentos de três } \\
\text { empresas. }\end{array}$ \\
\hline $\begin{array}{c}\text { Suprimen- } \\
\text { tos }\end{array}$ & $\begin{array}{c}\text { - Compras e aquisições são realizadas por meio de licitações ou dispensa de licitação (even- } \\
\text { tos extraordinários). No caso de artistas, é utilizado o processo de inexigibilidade, porque os } \\
\text { serviços prestados por eles são únicos e não têm comparação junto ao mercado. }\end{array}$ \\
\hline $\begin{array}{c}\text { Comunica- } \\
\text { ções }\end{array}$ & - As comunicações dentro do projeto são realizadas basicamente por e-mail e por telefone. \\
\hline
\end{tabular}

A orientação e o gerenciamento da execução do projeto são feitos pelo coordenador (gerente do projeto). As atividades são controladas conforme os objetivos, respeitando o ciclo de vida. Para auxiliar no controle, o projeto é revisado sempre que necessário. Já a avaliação e o controle são feitos por meio de reuniões envolvendo a equipe, com base na experiência em eventos anteriores, não utilizando para isso nenhuma métrica específica. O controle dos contratos é desenvolvido pela equipe de execução, que recebe auxílio da Divisão de Contratos. O encerramento é feito por meio da prestação de contas do evento, da finalização dos contratos, da avaliação do projeto e da apresentação de relatórios finais às instâncias superiores e de suas aprovações. No quadro 6 , são apresentadas, de forma resumida, as principais etapas do ciclo de vida de um projeto de evento desenvolvidas pela COC e pelos demais órgãos da universidade.

\begin{tabular}{|c|c|}
\hline Etapas & Atividades \\
\hline Iniciação & $\begin{array}{l}\text { - Realização do estudo de viabilidade econômica e de recursos materiais (não é relata- } \\
\text { do formalmente). } \\
\text { - Cadastramento do projeto no SigProj. } \\
\text { - Aprovação pelos órgãos superiores. }\end{array}$ \\
\hline Planejamento & $\begin{array}{l}\text { - Verificação do escopo, discriminando as atividades e as demais informações perti- } \\
\text { nentes, por meio de pauta de divisão de tarefas e da experiência da equipe. } \\
\text { - Seleção do gerente e da equipe do projeto (pessoas que atuam no setor proponente). } \\
\text { - Planejamento informal dos riscos, com base na experiência em projetos anteriores. } \\
\text { - Estimativa de custos e orçamentação baseada nos itens que o projeto utilizará. } \\
\text { - Contratações e aquisições feitas por meio de processo licitatório e de inexigibilidade. } \\
\text { - Comunicações dentro do projeto basicamente realizadas por e-mail e por telefone. }\end{array}$ \\
\hline Execução & $\begin{array}{l}\text { - Orientação e gerenciamento da execução do projeto são realizados pelo coordena- } \\
\text { dor. }\end{array}$ \\
\hline $\begin{array}{l}\text { Monitoramento } \\
\text { e Controle }\end{array}$ & $\begin{array}{l}\text { - Atividades controladas com base nos objetivos do projeto. } \\
\text { - Revisão do projeto sempre que necessário. } \\
\text { - Avaliação e controle realizado por meio de reuniões com o coordenador e com a } \\
\text { equipe. }\end{array}$ \\
\hline Encerramento & $\begin{array}{l}\text { - Controle dos contratos feito em conjunto com a Divisão de Contratos. } \\
\text { - Prestação de contas e encerramento dos contratos. } \\
\text { - Avaliação do projeto, apresentação de relatórios finais e aprovações. }\end{array}$ \\
\hline
\end{tabular}

Quadro 6 - Ciclo de vida de um típico projeto de evento da COC e da universidade.

Ao analisar as práticas de gestão de projetos culturais na organização, observa-se uma clara vinculação dessas práticas com o modelo de gestão no serviço público, notadamente marcado por regras burocráticas e exigências de legislação. No entanto, mesmo considerando os 
limites impostos pela burocracia, é possível observar que ainda existe abertura para que sejam feitas melhorias e adaptações em relação à maneira pela qual os projetos são conduzidos na universidade.

\subsection{0 caso da Mostra de Teatro 2010}

A Mostra de Teatro 2010 foi um projeto da COC que teve como objetivo a integração entre a universidade e a sociedade por meio das artes cênicas. Este evento se propôs à realização de espetáculos e de oficinas de teatro voltadas aos artistas e à comunidade. A análise do caso seguiu as etapas do ciclo de vida de um projeto, conforme mostra o quadro 7.

\begin{tabular}{|c|c|}
\hline Etapas & Atividades \\
\hline Iniciação & $\begin{array}{l}\text { - Reunião com a equipe e o coordenador, para definir o escopo do evento e seus objetivos. } \\
\text { - Cadastramento do projeto no SigProj. } \\
\text { - Aprovação do projeto pelos órgãos superiores. } \\
\text { - Contato com os artistas participantes da Mostra. }\end{array}$ \\
\hline Planejamento & $\begin{array}{l}\text { - Contratação dos artistas, com abertura de processos de inexigibilidade. Esse proces- } \\
\text { so apresenta a análise de custos e orçamento e é encaminhado ao setor de Compras. } \\
\text { - Pedido de empenho recebido e repassado aos contratados. } \\
\text { - Assinatura dos contratos com os artistas e prestadores de serviços licitados. } \\
\text { - Reserva do Teatro Municipal, de hospedagem e de transporte terrestre e aéreo. } \\
\text { - Concepção do material gráfico e divulgação do evento. }\end{array}$ \\
\hline Execução & $\begin{array}{l}\text { - Acompanhamento da organização das necessidades técnicas dos espetáculos. } \\
\text { - Controle da equipe do cerimonial e do "anjo". } \\
\text { - Registro fotográfico e filmagem do evento e realização dos espetáculos e da oficina. }\end{array}$ \\
\hline $\begin{array}{c}\text { Monitoramento } \\
\text { e Controle }\end{array}$ & - Controle das atividades pela equipe e pelo coordenador do projeto. \\
\hline Encerramento & $\begin{array}{l}\text { - Confecção dos certificados da equipe e dos participantes da oficina. } \\
\text { - Quitações financeiras, após a apresentação de nota fiscal. } \\
\text { - Relatórios finais e suas aprovações. }\end{array}$ \\
\hline
\end{tabular}

Quadro 7 - Ciclo de vida da Mostra de Teatro 2010.

Antes de iniciar o projeto, foi realizada uma reunião com os membros da equipe administrativa, composta pelos funcionários da $\mathrm{COC}$ e pelo coordenador do projeto, para definir o escopo do evento e seus objetivos. A iniciação ocorreu por meio do seu cadastramento no SigProj, momento em que foram inseridas as seguintes informações: identificação da ação, período, público-alvo, parcerias, resumo, justificativa, objetivos, forma de avaliação, equipe de execução, cronograma, descrição financeira etc. Após o cadastramento do projeto, este foi encaminhado via sistema e via documento impresso para as instâncias superiores. Em cada uma das instâncias foram expedidas resoluções de aprovação.

Para a contratação dos artistas, foi necessário abrir processos de inexigibilidade. Para isso, foram apresentadas todas as informações referentes ao contratado (necessidades técnicas, número de integrantes, passagens e hospedagem). Após a abertura do processo, foi feita a análise de custos, com apresentação de três documentos que comprovaram valor semelhante ao ser contratado e os documentos que comprovaram a legalidade da pessoa jurídica ou física a ser contratada. Em seguida, o processo foi encaminhado para o setor de Compras. Depois dos trâmites, o pedido de empenho foi encaminhado à $\mathrm{COC}$, que correspondia à comprovação de que o recurso estava destinado àquele fim. Após a emissão do pedido de empenho, os contratos 
foram assinados (prestadores de serviços e artistas). Paralelamente, foram reservados o local do evento, a hospedagem e o transporte. Na fase de planejamento, também foi concebido o material gráfico para a divulgação do evento.

Durante a execução do evento, um acompanhamento foi realizado, principalmente em relação às necessidades técnicas (som, iluminação, palco, camarim, entre outras). A equipe responsável pelo cerimonial também foi formada, pois esta tinha como responsabilidades: recepção dos espectadores, portaria, troca de ingressos, cerimonial de palco e de oficinas. Também durante a execução, foi designado o "anjo" (responsável por acompanhar os grupos teatrais) e o responsável pela fotografia e filmagem do evento. Após a realização do evento, foram confeccionados os certificados para os participantes e para a equipe de organização.

No encerramento, as quitações financeiras e os relatórios finais do projeto foram efetuados. Os relatórios foram encaminhados para aprovação pelos órgãos superiores.

\subsection{Fatores críticos na gestão de projetos da COC e da universidade}

A gestão dos projetos de eventos organizados pela COC e pela instituição apresenta divergências quando comparada com os modelos presentes na literatura. Os fatores críticos identificados na $\mathrm{COC}$ e na universidade objeto de estudo foram tratados como pontos negativos que necessitam de uma maior atenção por porte dos gestores de projetos. Algumas das divergências que foram identificadas estavam relacionadas com as particularidades da gestão de eventos e com o modelo de gestão de uma instituição pública. No entanto, muitas das divergências devemse à falta de capacitação profissional na gestão de projetos. Assim, no âmbito desta pesquisa, os fatores que demonstraram a falta de capacitação em gestão de projetos foram denominados de "fatores críticos".

O principal ponto negativo apontado pela pesquisa é que o planejamento, a execução e o controle do projeto são feitos sem nenhuma metodologia que seja orientada para o gerenciamento do evento como um projeto. Embora os procedimentos adotados estejam sujeitos às regulamentações que uma instituição pública normalmente impõe, as ações que são de responsabilidade dos gestores e que vão além dos procedimentos burocráticos são baseadas puramente na intuição e na experiência dos organizadores do evento, sem uma sistematização do conhecimento por meio de uma metodologia de gerenciamento de projetos. No quadro 8, são apresentados os pontos críticos em relação à gestão de eventos segundo as diferentes áreas do conhecimento em gestão de projetos.

\begin{tabular}{|c|l|}
\hline Áreas & \multicolumn{1}{c|}{ Pontos críticos } \\
\hline Gestão da integração & - Não são criados planos do projeto. \\
\hline Gestão do escopo & $\begin{array}{l}\text { - Planos de escopo não são feitos de maneira formal. } \\
\text { - Não são utilizadas ferramentas e técnicas específicas para a gestão do escopo, } \\
\text { tais como a Estrutura Analítica do Projeto. }\end{array}$ \\
\hline Gestão do tempo & $\begin{array}{l}\text { - O cronograma não é feito formalmente. } \\
\text { - Não são utilizadas ferramentas de gerenciamento do tempo, tais como o crono- } \\
\text { grama ou a rede de atividades para a identificação do caminho crítico. }\end{array}$ \\
\hline Gestão de custos & $\begin{array}{l}\text { - Há um controle rígido e não são aceitas muitas alterações, pois se trata de uma } \\
\text { instituição pública, sujeita a um alto grau de regulamentação de procedimentos. }\end{array}$ \\
\hline Gestão da qualidade & - Não é realizado nenhum procedimento referente à gestão da qualidade. \\
\hline $\begin{array}{c}\text { Gestão de recursos } \\
\text { humanos }\end{array}$ & $\begin{array}{l}\text { - A equipe é formada pelos servidores do setor, os quais nem sempre são capaci- } \\
\text { tados para as atividades demandadas pelo projeto. }\end{array}$ \\
\hline
\end{tabular}




\begin{tabular}{|c|l|}
\hline Áreas & \multicolumn{1}{c|}{ Pontos críticos } \\
\hline $\begin{array}{c}\text { Gestão das } \\
\text { comunicações }\end{array}$ & $\begin{array}{l}\text { - Informações são distribuídas somente quando solicitadas; não existe uma abor- } \\
\text { dagem planejada para a gestão das comunicações. }\end{array}$ \\
\hline Gestão dos riscos & $\begin{array}{l}\text { - Não se faz avaliação de riscos. } \\
\text { - Não há elaboração formal de um plano contingencial. }\end{array}$ \\
\hline $\begin{array}{c}\text { Gestão de } \\
\text { suprimentos }\end{array}$ & $\begin{array}{l}\text { - Ênfase excessiva na avaliação de custos, com pouca possibilidade de inclusão } \\
\text { de critérios técnicos para a seleção de fornecedores. }\end{array}$ \\
\hline
\end{tabular}

Quadro 8 - Pontos críticos na gestão de eventos culturais da universidade.

Após a identificação dos fatores críticos, foram desenvolvidas algumas proposições de melhoria em relação à gestão de projetos para eventos culturais para a $\mathrm{COC}$, conforme é possível visualizar no quadro 9, que apresenta as atividades que devem ser desenvolvidas em cada uma das etapas do ciclo de vida de um projeto de evento cultural. Com o mesmo intuito, no quadro 10 é sugerida a aplicação de algumas ferramentas típicas de gestão de projetos que seriam adequadas às características dos eventos culturais promovidos pela universidade.

\begin{tabular}{|c|c|c|}
\hline Ciclo de vida & Áreas & Atividades \\
\hline Iniciação & Todas as áreas & $\begin{array}{l}\text { - Cadastramento do projeto no SigProj } \\
\text { - Escolha do coordenador - definição de suas responsabilidades } \\
\text { - Estudo de viabilidade e aprovações }\end{array}$ \\
\hline \multirow{9}{*}{ Planejamento } & Integração & - Elaboração do plano de gerenciamento do projeto \\
\hline & Escopo & $\begin{array}{l}\text { - Elaboração do plano de ação e controle do escopo } \\
\text { - Desenvolvimento da EAP }\end{array}$ \\
\hline & Tempo & $\begin{array}{l}\text { - Desenvolvimento do cronograma } \\
\text { - Identificação do caminho crítico e das folgas das atividades }\end{array}$ \\
\hline & Custos & $\begin{array}{l}\text { - Identificação de todos os recursos necessários } \\
\text { - Estimativa de custos e orçamentação }\end{array}$ \\
\hline & Qualidade & $\begin{array}{l}\text { - Elaboração do plano de gestão da qualidade } \\
\text { - Definição de indicadores de desempenho }\end{array}$ \\
\hline & $\begin{array}{l}\text { Recursos hu- } \\
\text { manos }\end{array}$ & $\begin{array}{l}\text { - Definição da equipe e de suas atividades } \\
\text { - Capacitação e treinamento da equipe }\end{array}$ \\
\hline & Comunicações & - Elaboração do plano de distribuição das informações \\
\hline & Riscos & $\begin{array}{l}\text { - Identificação e avaliação dos riscos } \\
\text { - Elaboração do plano de respostas aos riscos e do plano de contin- } \\
\text { gência }\end{array}$ \\
\hline & Suprimentos & - Elaboração do plano de aquisições e contratações \\
\hline Implementação & Todas as áreas & $\begin{array}{l}\text { - Orientação e gerenciamento das atividades } \\
\text { - Contato constante com os fornecedores } \\
\text { - Reuniões periódicas para verificação do andamento das atividades }\end{array}$ \\
\hline $\begin{array}{c}\text { Monitoramento } \\
\text { e Controle }\end{array}$ & Todas as áreas & $\begin{array}{l}\text { - Acompanhamento de indicadores de desempenho } \\
\text { - Atualização e revisão de todos os planos } \\
\text { - Análise e controle de mudanças }\end{array}$ \\
\hline Encerramento & Todas as áreas & $\begin{array}{l}\text { - Encerramento de contratos e prestação de contas } \\
\text { - Avaliação final do projeto } \\
\text { - Relatórios finais e aprovações }\end{array}$ \\
\hline
\end{tabular}


GESTÃO DE PROJETOS DE EVENTOS CULTURAIS EM UMA UNIVERSIDADE PÚBLICA FEDERAL: ANÁLISE DE PRÁTICAS E PROPOSIÇÃO DE MELHORIAS

\begin{tabular}{|c|c|l|}
\hline Ciclo de vida & Áreas do conhecimento & \multicolumn{1}{c|}{ Ferramentas } \\
\hline Iniciação & Todas as áreas & - Termo de abertura do projeto \\
\hline \multirow{4}{*}{ Planejamento } & Integração & - Plano integrado de gerenciamento do projeto \\
\cline { 2 - 3 } & Escopo & - EAP (Estrutura Analítica do Projeto) \\
\cline { 2 - 3 } & Tempo & $\begin{array}{l}\text { - Cronograma (Gráfico de Gantt) } \\
\text { - Rede PERT/CPM }\end{array}$ \\
\cline { 2 - 3 } & Custos & $\begin{array}{l}\text { - Planilha de recursos } \\
\text { - Cronograma físico-financeiro }\end{array}$ \\
\cline { 2 - 3 } & Qualidade & - Painel de indicadores de desempenho \\
\cline { 2 - 3 } & Comunicações & - Quadriz de responsabilidades de distribuição de informações \\
\cline { 2 - 3 } & Riscos & - Quadro de avaliação de riscos \\
\cline { 2 - 3 } & Suprimentos & - Quadro de aquisições e contratações \\
\cline { 2 - 3 } & Todas as áreas & - Formulário de acompanhamento de reuniões periódicas \\
\hline Implementação & Todas as áreas & - Painel de indicadores de desempenho \\
\hline Monitoramento & - Formulários de controle de mudanças \\
\hline \multirow{2}{*}{$\begin{array}{c}\text { Encerramento } \\
\text { entrole }\end{array}$} & Todas as áreas & $\begin{array}{l}\text { - Formulário padrão para a prestação de contas } \\
\text { - Formulário padrão para a elaboração de relatórios finais }\end{array}$ \\
\hline
\end{tabular}

Quadro 10 - Ferramentas de gestão de projetos propostas para a COC.

Ao adotar as atividades e as ferramentas sugeridas nos quadros 9 e 10, a Coordenadoria de Cultura deverá aperfeiçoar suas práticas de forma incremental em um ciclo de melhoria contínua, de modo a reduzir pontos negativos e incorporar melhorias ao processo de aprendizagem dos agentes envolvidos na gestão de projetos (KOTNOUR, 2000). A melhoria gradual de práticas poderia influenciar no desenvolvimento de uma metodologia singular para a gestão de projetos de eventos culturais realizados pela universidade, aumentando a probabilidade de sucesso desses projetos. Assim, o sucesso de um projeto cultural desenvolvido pela COC dependerá da capacidade do gestor de projeto de equilibrar as expectativas dos diferentes stakeholders de acordo com os recursos disponíveis e de envolvê-los no processo de planejamento, utilizando para isso uma abordagem adequada à gestão de projetos.

\section{CONCLUSÃO}

Este trabalho explicitou as práticas de gestão de projetos de eventos culturais na organização estudada e contribuiu para que os responsáveis por esta atividade pudessem caminhar em direção ao desenvolvimento de competências nessa área. No campo teórico, este artigo discutiu aspectos específicos relacionados ao gerenciamento de projetos de eventos culturais, traçando as semelhanças entre a gestão de projetos de uma forma geral e a gestão de projetos de eventos. Tal aspecto representa uma contribuição relevante em nível conceitual, pois grande parte dos trabalhos na área aborda a gestão de eventos sob o enfoque da literatura de turismo, sem uma influência significativa da literatura de gestão de projetos.

Do ponto de vista do trabalho empírico, esta pesquisa possibilitou desenvolver uma análise detalhada sobre as práticas de gestão de eventos culturais adotadas por uma universidade federal, especialmente sobre as práticas adotadas pela Coordenadoria de Cultura. Por meio da pesquisa, pôde-se obter uma maior compreensão sobre o gerenciamento e a organização de projetos de eventos dentro da organização. Essa compreensão permitiu observar algumas particularidades na gestão de eventos, pois, como se trata de uma instituição pública, necessita 
de processos específicos, geralmente relacionados com a burocracia do setor público e com as restrições impostas pela legislação.

Também foi possível constatar que a gestão de projetos de eventos organizados pela COC e pela instituição apresenta alguns fatores críticos quando comparada com os modelos presentes na literatura. Dentre os aspectos negativos que foram observados, destaca-se a inexistência de uma metodologia para a gestão de eventos na organização, deixando essa tarefa a cargo da intuição e da experiência dos gestores.

Com base nos pontos críticos apontados pela pesquisa, foi possível desenvolver algumas proposições de melhoria para a gestão dos projetos de eventos culturais coordenados pela $\mathrm{COC}$, principalmente em relação à adoção de ferramentas de gestão de projetos e às atividades que devem ser executadas em cada uma das fases do ciclo de vida.

Considerando que a COC ainda se encontra em fase de estruturação, mas que vem se expandindo e se tornando um grande centro de promoção de eventos culturais, a mesma apresenta um potencial de atingir a maturidade no gerenciamento de projetos. Sendo assim, na continuidade desta pesquisa sugere-se que seja desenvolvida uma metodologia específica de gerenciamento de projetos de eventos culturais que atenda às necessidades singulares da organização estudada.

Explorando novas possibilidades de pesquisa, sugere-se uma ampliação da amostra para que sejam analisadas e comparadas as práticas de gestão de eventos em diferentes universidades, de modo a obter um panorama mais amplo dessa problemática e identificar os aspectos da gestão de projetos de eventos que podem ser generalizados e que certamente demandariam soluções em comum. Com esta finalidade, uma abordagem quantitativa de pesquisa poderia ser mais adequada, realizando uma análise estatística a partir da coleta de dados provenientes de uma amostra representativa.

\section{REFERÊNCIAS}

ALLEN, J. et al. Organização e gestão de eventos. Rio de Janeiro: Elsevier, 2003.

AZEVEDO, C. A. M.; AZEVEDO, A. G. Metodologia científica: contributos práticos para a elaboração de trabalhos acadêmicos. 9. ed. Lisboa: Universidade Católica Editora, 2008.

BRITTO, J.; FONTES, N. Estratégias para eventos: uma ótica do marketing e do turismo. São Paulo: Editora Aleph, 2002.

BROWNING, T. R. On the alignment of the purposes and views of process models in project management. Journal of Operations Management, v. 28, n. 4, p. 316-332, 2010.

BRYDE, D. J. Project management: concepts, methods and application. International Journal of Operations \& Production Management, v. 23, n.7, p. 775-793, 2003.
CANTON, M. Evento: da proposta ao planejamento. Turismo Visão e Ação, v. 1, n. 1, p.101-113, 1998.

CARVALHO, M. M.; RABECHINI JR., R. Construindo competências para gerenciar projetos: teoria e casos. São Paulo: Atlas, 2005.

CASADO, F. L.; SILUK, J. C. M.; ZAMPIERI, N. L. V. Universidade empreendedora e o desenvolvimento regional sustentável: proposta de um modelo. Revista de Administração da UFSM, v. 5, p. 633-649, 2013.

DINSMORE, P. C.; SILVEIRA NETO, F. H. Gerenciamento de projetos: como gerenciar seu projeto com qualidade dentro do prazo e custos previstos. Rio de Janeiro: Qualitymark, 2004.

DOOLEY, L.; LUPTON, G.; O'SULLIVAN, D. Multiple project management: a modern competitive necessity. Journal of Manufacturing Technology Management, v. 
16, n. 5, p. 466-482, 2005.

DUARTE, C. C. M. et al. Análise do conceito de sucesso aplicado ao gerenciamento de projetos de tecnologia da informação. Revista de Administração da UFSM, v. 5, n. 3, p. 459478, 2012.

GALVÃO, H. M.; CORRÊA, H. L.; ALVES, J. L. Modelo de avaliação de desempenho global para instituição de ensino superior. Revista de Administração da UFSM, v. 4, n. 3, p. 425-441, 2011.

JUGDEV, K.; MÜLLER, R. A retrospective look at our evolving understanding of project success. Project Management Journal, v. 36, n. 4, p. 1531, 2005.

KERZNER, H. Gestão de projetos: as melhores práticas. 2. ed. Porto Alegre: Bookman, 2006.

KOTNOUR, T. Organizational learning practices in the project management environment. International Journal of Quality \& Reliability Management, v. 17, n. 4/5, p. 393-406, 2000.

LAKATOS, E. M.; MARCONI, M. A. Fundamentos de metodologia científica. 2. ed. São Paulo: Atlas, 1990.

LASZLO, G. P. Project management: a quality management approach. The TQM Magazine, v. 11, n. 3, p. 157-169, 1999.

LONGMAN, A.; MULLINS, J. Project management: key tool for implementing strategy. Journal of Business Strategy, v. 25, n. 5, p. 54-60, 2004.

MALACH-PINES, A.; DVIR, D.; SADEH, A. Project manager-project (PM-P) fit and project success. International Journal of Operations \& Production Management, v. 29, n. 3, p. 268291, 2009.

MARTIN, V. Manual prático de eventos. São Paulo: Atlas, 2003.

MORRIS, P. W. G.; JAMIESON A. Moving from corporate strategy to project strategy. Project
Management Journal, v. 36, n. 4, p. 5-18, 2005.

PEREIRA, G.; CANTO, S. M. de. Educación ambiental y planificación de un evento turístico: los desfiles y las Olimpíadas Coloniales de la Fiesta Nacional de la Uva - RS, Brasil. Estudios y Perspectivas en Turismo, v. 18, p. 511-529, 2009.

PMI - PROJECT MANAGEMENT INSTITUTE. Um guia do conjunto de conhecimentos em gerenciamento de projetos (Guia PMBoK). 3. ed. Newtown Square: PMI, 2004.

PRADO, D. S. Planejamento e controle de projetos. 6. ed. Nova Lima, MG: INDG, 2004.

RABECHINI JR., R.; PESSÔA, M. S. P. Um modelo estruturado de competências e maturidade em gerenciamento de projetos. Produção, v. 15, n. 1, p. 34-43, 2005.

REID, S. Event stakeholder management: developing sustainable rural. International Journal of Event and Festival Management, v. 2, n. 1, p. 20-36, 2011.

REVERTÉ, F. G.; IZARD, O. M. The role of social and intangible actors in cultural event planning in Catalonia. International Journal of Event and Festival Management, v. 2, n. 1, p. 37-53, 2011.

WHITE; M. D.; MARSCH, E. E. Content analysis: a flexible methodology. Library Trends, v. 55, n. 1, p. 22-45, 2006.

YOUNG, R. et al. Is strategy being implemented through projects? Contrary evidence from a leader in New Public Management. International Journal of Project Management, v. 30, n. 8, p. 887-900, 2012. 